\title{
Mass-Spectrometric Investigations of Silver Clusters
}

\author{
M. Szymanska-Chargot ${ }^{a, *}$, A. GruszeckA ${ }^{b}$, A. Smolira $^{b}$ And K. Bederski ${ }^{b}$ \\ ${ }^{a}$ Institute of Agrophysics, Polish Academy of Sciences, Doświadczalna 4, 20-290 Lublin, Poland \\ ${ }^{b}$ Institute of Physics, Maria Curie-Skłodowska University, pl. M. Curie-Skłodowskiej 1, 20-031 Lublin, Poland
}

(Received March 28, 2011)

\begin{abstract}
We report results of experimental studies on the silver clusters formation in laser desorption and matrix assisted laser desorption. Time-of-flight mass spectrometer was used to control process itself. Firstly, we investigated dependence of silver salts of variety chemical nature on formation of silver clusters. The most prominent was usage of organic silver salts (silver trifluoroacetate and silver benzoate). The biggest species obtained was $\mathrm{Ag}_{45}^{+}$ (silver benzoate). Secondly, we examined influence of organic matrix (2,5-dihydroxybenzoic acid) on formation efficiency of silver clusters in matrix assisted laser desorption. In all cases we observed increase of silver clusters size.
\end{abstract}

PACS: 33.80.-b, 34.80.Gs

\section{Introduction}

Investigation of cluster formation by mass spectrometry tools has been an effective approach to gain valuable information on the ion-molecule reactions, ion-induced nucleation or stability and electronic properties of clusters. The past decades brought development of number of cluster production techniques. The most commonly used method of cluster produce is laser vaporization technique $[1,2]$. In this method, the metal vapors are generated by laser impulse and then vapor is expanded in presence of carrier gas. Another method involves metal vaporization by heating and then metal aggregation in presence of carrier gas [3]. Apart from these methods, ion-bombardment or laser ablation of metals were also introduced [4-7]. Previously, authors investigated electrochemical process of cluster production [8], as well as influence of UV radiation on cluster formation [9].

The method applied in this work was direct formation of silver clusters from silver salts in laser desorption/ionization process connected with mass spectrometry. This method was previously applied with success to carbon clusters formation [10]. In addition we investigate influence of organic matrix on silver clusters formation (matrix assisted laser desorption/ionization, MALDI). Also, we proposed possible ion-molecule reactions which might take place in ion source [11]. Recently, many of researchers have used both laser desorption/ionization method and matrix assisted laser desorption/ionization method incorporated to silver cluster formation from different silver salts [12-15].

\section{Experimental}

All chemicals: silver nitrate, silver chloride, silver carbonate, silver trifluoroacetate (AgTFA), silver ben-

* corresponding author; e-mail: m.szymanska@ipan.lublin.pl zoate $(\mathrm{AgBz})$, silver nanopowder $(<100 \mathrm{~nm})$ and matrix 2,5-dihydroxybenzoic acid (DHB) chosen for the investigations presented here were purchased from Sigma Aldrich and used without further purification. All silver salts were dissolved in distilled water $\left(10^{-2} \mathrm{M}\right)$. Silver nanopowder was only distributed in distilled water because of its insolubility in water. For the control of silver clusters growth time-of-flight mass spectrometer (TOF MS) (constructed by L. Michalak and coworkers in Department of Molecular Physics, Institute of Physics, M. Curie-Skłodowska University, Lublin, Poland) was used (Fig. 1). The TOF mass spectrometer has been described in detail previously $[16,17]$.

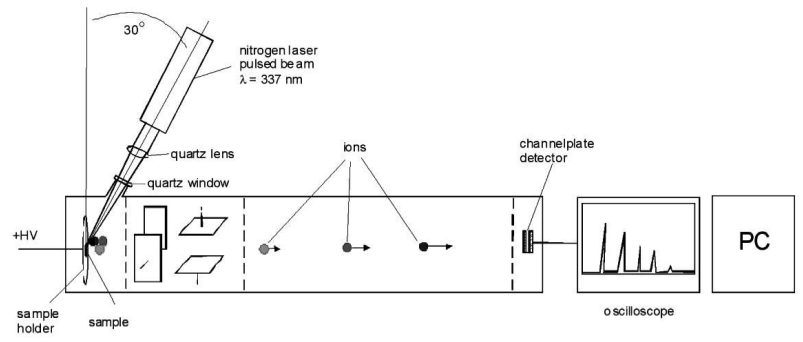

Fig. 1. Schematic view of the time-of-flight mass spectrometer (TOF MS).

Briefly, the nitrogen laser (LN 300C; Laser Photonics) has a wavelength of $337 \mathrm{~nm}$, an output length of $5 \mathrm{~ns}$, maximum pulse energy specified as $250 \mu \mathrm{J}$ and rectangular output shape of approximately $4 \mathrm{~mm} \times 9 \mathrm{~mm}$. The angle of laser beam, which was focused in the plane of the sample, is $30^{\circ}$. In this case the calculated dimensions of the laser beam spot were approximately $400 \times 900 \mu \mathrm{m}^{2}$ and the power density was $\approx 14 \mathrm{MW} \mathrm{cm}^{-2}$. An ion acceleration voltage of $17 \mathrm{kV}$ was applied to the sample holder. The ions were detected by two-channel plate (Hamamatsu) ion detector operated at $2.3 \mathrm{kV}$. Data were acquired with a $500 \mathrm{MHz}(1 \mathrm{G}$ sample/s) digital oscillo- 
scope (Hewlett Packard HP 54615B). The mass spectra were collected using both positive and negative ion modes and were averaged by 256 laser shots. The spectra were then transferred to a PC for processing.

There are many methods of sample preparation in the laser desorption method, the most commonly used one is the dried-droplet method $[18,19]$. This method was applied for investigations presented here. In case of direct laser desorption/ionization the volume of $20 \mu \mathrm{l}$ of the investigated mixture were placed on the sample holder and dried in air at room temperature giving a visible and apparently homogeneous spot of $\approx 10 \mathrm{~mm}$ diameter and $0.1 \mathrm{~mm}$ thickness. In case of matrix assisted laser desorption/ionization investigations, there were prepared solutions of matrix in concentration of $0.08 \mathrm{M}$ and silver salts: silver nitrate, $\mathrm{AgTFA}$ and $\mathrm{AgBz}(0.09 \mathrm{M})$ all dissolved in water. The solutions of matrix and each silver salt were mixed in a $5: 1 \mathrm{v} / \mathrm{v}$ ratio (matrix/silver salt). Volume of $20 \mu \mathrm{l}$ of these solutions was deposited onto the flat stainless steel sample holder and then whole procedure was the same like it was described above.

\section{Results and discussion}

\subsection{Direct formation of silver clusters in laser desorption/ionization (LDI)}

Figure $2 \mathrm{a}$ and $\mathrm{b}$ presents positive and negative mass spectra of silver nitrate, respectively. Apart of positive ions of bare silver clusters $\operatorname{Ag}_{n}^{+}(n=2-5)$ there is evidence of silver clusters compounds formation, mainly with oxygen $\mathrm{Ag}_{n} \mathrm{O}_{m}^{+}(n=1-5, m=1-6)$ and hydrogen $\left(\mathrm{Ag}_{2} \mathrm{O}_{5} \mathrm{H}_{8}^{+}\right.$and $\left.\mathrm{Ag}_{4} \mathrm{O}_{4} \mathrm{H}_{8}^{+}\right)$. In case of negative ions, $\mathrm{Ag}_{n}^{-}(n=1-4)$ ions of bare silver cluster and oxygenated silver clusters $\mathrm{Ag}_{n} \mathrm{O}_{m}^{-}(n=1-4, m=1-6)$ are formatted. Interesting result is presence of oxygen clusters ions, both positive $\mathrm{O}_{m}^{+}(m=2,3)$ and negative $\mathrm{O}_{m}^{-}(m=1-5)$. Irradiation of silver nitrate leads to thermal heating and in consequence to its decomposition according to the following reaction:

$$
2 \mathrm{AgNO}_{3} \rightarrow 2 \mathrm{Ag}+2 \mathrm{NO}_{2}+\mathrm{O}_{2} .
$$

The products obtained in the reaction are likely to go under further ion-molecular reactionsspeculate, to form additional secondary ions, for example

$$
\begin{aligned}
& \mathrm{Ag}_{2}^{+}+\mathrm{O}_{2} \rightarrow \mathrm{Ag}_{2} \mathrm{O}_{2}^{+}, \\
& \mathrm{Ag}_{2} \mathrm{O}_{2}^{+} \rightarrow \mathrm{Ag}_{2} \mathrm{O}^{+}+\mathrm{O}, \\
& \mathrm{Ag}_{2} \mathrm{O}_{2}^{+}+\mathrm{O}_{2} \rightarrow \mathrm{Ag}_{2} \mathrm{O}_{4}^{+} .
\end{aligned}
$$

Observed peaks of both silver clusters and their compounds are clearly broadened. This is due to the fact that silver occurs naturally as a mixture of two stable isotopes: ${ }^{107} \mathrm{Ag}(51.8 \%)$ and ${ }^{109} \mathrm{Ag}(48.2 \%)$. In the mass spectrum, peak corresponding to the $\mathrm{Ag}^{+}$ion in fact consists of two peaks, corresponding to silver isotopes. Similarly, the other peaks, for example, $\mathrm{Ag}_{2} \mathrm{O}^{+}$probably consists of the following combinations of isotopes of silver and oxygen atoms: ${ }^{107} \mathrm{Ag}_{2} \mathrm{O}^{+},{ }^{107} \mathrm{Ag}^{109} \mathrm{AgO}^{+}$and
${ }^{109} \mathrm{Ag}_{2} \mathrm{O}^{+}$. The intensity of the ionic currents created by the negative ions of silver clusters $\mathrm{Ag}_{n}^{-}(n=2-4)$ show less intensity than the ionic currents created by positive ions. This may be related to the fact that silver has one electron valence shell, so the oxidation state is +1 .

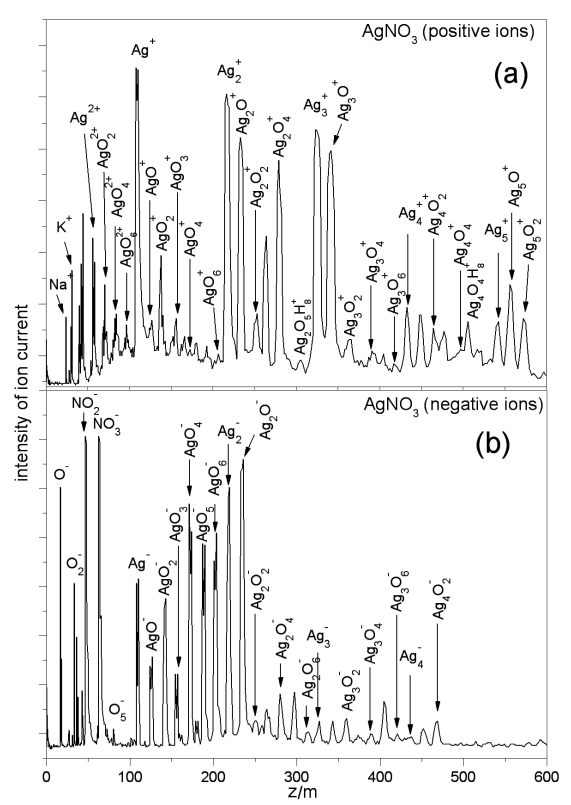

Fig. 2. (a) Positive-ions mass spectra of silver nitrate obtained in laser desorption/ionization. (b) Negative-ions mass spectra of silver nitrate obtained in laser desorption/ionization.

One of the salt commonly used in studies on the formation of silver clusters in the MALDI process is silver trifluoroacetate $\mathrm{CF}_{3} \mathrm{COOAg}[12-14]$. Mass spectra for positive and negative ions formed in the process of laser desorption/ionization of silver trifluoroacetate are presented in Fig. 3a and b, respectively. In the case of positive ions we obtained $\mathrm{Ag}_{n}^{+}$clusters with the number $n \leq 11$, while in the case of negative ions we observe a small volume of the ionic currents created by clusters $\operatorname{Ag}_{n}^{-}(n \leq 5)$. Moreover, in the spectrum of positive and negative ions we have a large number of silver compounds with fluorine and hydrogen constituting silver trifluoroacetate: $\operatorname{Ag}_{n} \mathrm{~F}_{m}^{+}(n=1-7, m=1-4), \mathrm{Ag}_{n} \mathrm{~F}_{m} \mathrm{H}_{k}^{+}$ $(n=1-11, m=1-4, k=1-4)$.

In Fig. 4a there is presented the mass spectrum created by positive ions obtained by laser desorption/ionization of silver benzoate. There are registered large numbers of positive ions of silver clusters $\mathrm{Ag}_{n}^{+}(n=2-45)$. It is also apparent alternation in the rate of ionic currents of clusters due to an even or odd number of silver atoms in the cluster (Fig. 5). The magic clusters formed by ions $\mathrm{Ag}_{9}^{+}$ and $\mathrm{Ag}_{21}^{+}$are observed. The studies have shown that production efficiency of silver clusters by laser desorption is greatest in the case of silver benzoate. This is probably because the molecules of this compound at the time of evaporation of water crystallize to form compound con- 


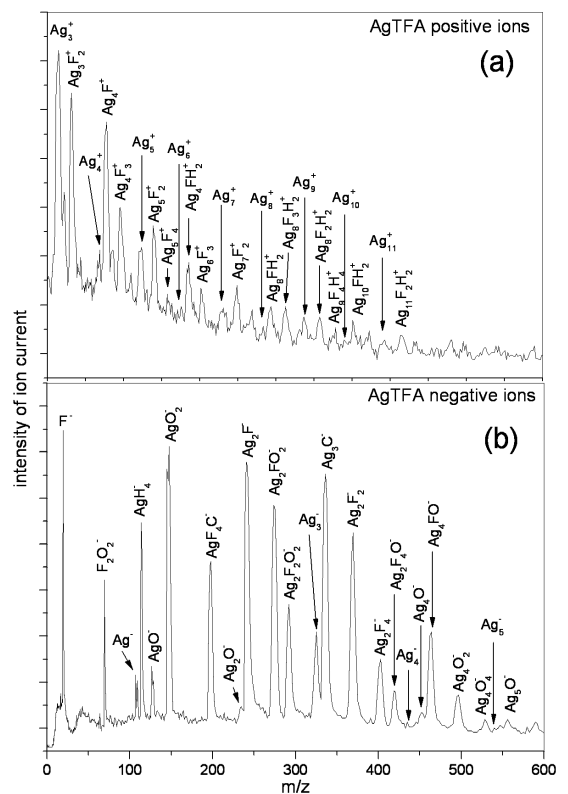

Fig. 3. As in Fig. 2, but for silver trifluoroacetate.

sisting of two molecules. During the laser desorption/ ionization, as a result of photochemical processes, are created structures consisting more silver atoms [13]. There was also collected negative ion spectrum (Fig. 4b). It indicates the formation of only small clusters of silver compounds of carbon and hydrogen negative ions.

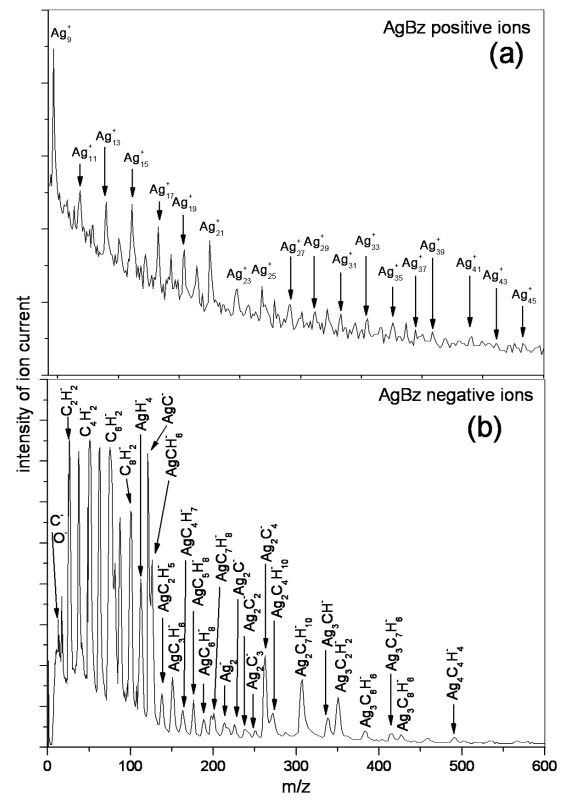

Fig. 4. As Fig. 2, but for silver benzoate.

The results of silver clusters formation during laser desorption/ionization of silver salts are summarized in Table I. Apart silver salts mentioned above, results obtained for silver chloride, silver carbonate and silver

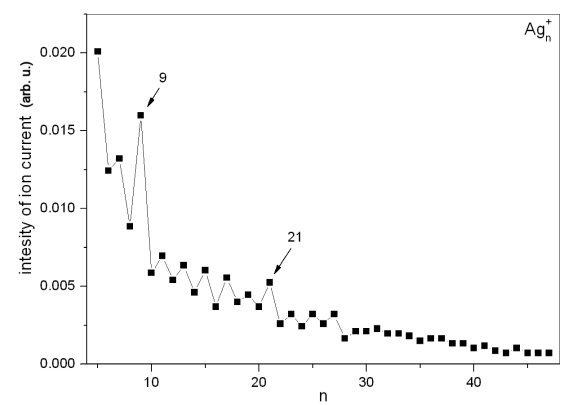

Fig. 5. Intensity of ionic currents of clusters in function of clusters sizes. Positive ions obtained by laser desorption/ionization of silver benzoate.

nanopowder are taken into consideration.

TABLE I

Ions of the largest clusters sizes obtained in LDI method, depending on the type of salt used.

\begin{tabular}{c|c|c}
\hline \hline \multirow{2}{*}{ Silver compound } & \multicolumn{2}{|c}{$n$} \\
\cline { 2 - 3 } & $\mathrm{Ag}_{n}^{+}$ & $\mathrm{Ag}_{n}^{-}$ \\
\hline silver nitrate & 5 & 4 \\
silver carbonate & 3 & 2 \\
silver chloride & 5 & 3 \\
silver trifluoroacetate & 11 & 5 \\
silver benzoate & 45 & 2 \\
silver nanopowder & 37 & -
\end{tabular}

The question that appeared after examining a series of mass spectra presented here should be as follows: what is the mechanism behind the formation of clusters during the laser desorption of salt containing silver? In general, in the literature there could be found two such processes:

1. silver clusters are formed in the condensed phase by photochemical processes and/or other chemical processes accompanying laser desorption/ionization,

2. silver clusters are formed in the gas phase, occurring during silver salt evaporation in laser desorption/ionization, as a result of ion-molecule reactions [14].

Based on the results obtained, it can be assumed that, depending on the used material, there appeared one of the above processes. For example, according to the first mechanism, positive ions of silver clusters derived from silver nanopowder are formed likely. Clusters or nanostructures can be created in two ways: either by synthesis (e.g. any method of obtaining fullerenes) or by reducing (e.g. mechanical grinding of crystal structures). Silver nanopowder is generally milled crystalline silver, so probably clusters (or nanostructures) of silver are already in 
the crystal phase, and the process of laser desorption/ ionization by photochemical processes results in their release to the vacuum of the mass spectrometer.

A similar mechanism is postulated in the case of silver benzoate, as mentioned above, although we obtained larger silver clusters so perhaps we are dealing with both mechanisms. By contrast, examining the mass spectrum of ions obtained by laser desorption/ionization of silver salts such as silver nitrate, silver chloride, silver carbonate or silver trifluoroacetate, which abound in the molecular ions, formed probably as a result of ion-molecular reaction mechanism, are subject to second one.

Concluding, probability of production of silver clusters by laser desorption is greater if there are already the seeds of diatomic clusters in the condensed phase (as is likely in the case of silver benzoate). On the other hand, if clusters are already in the condensed phase, in this case the use of a matrix (MALDI method) is pointless, whose influence is mostly in the gas phase. The matrix should therefore be useful when examining the silver salts, but would be useless in silver nanopowder case.

\subsection{Influence of matrix on formation of silver clusters (MALDI)}

In the analysis of different materials silver salts are added often to the mixture of matrix and analyte as cationization agent. Silver cations are reduced to form clusters of silver during the laser desorption. This allowed to believe that the matrix used in MALDI method can affect the formation of silver clusters. In the literature one can find studies using silver compounds and organic matrices of various chemical nature [13-15]. In the presented work, three salts of silver were selected: silver nitrate, silver trifluoroacetate and silver benzoate, and as a matrix there was used DHB (154 Da). These compounds are often used in the study of silver clusters by laser desorption/ionization matrix assisted.

For all studied silver salts increase in the number of positive ions of produced silver clusters $\mathrm{Ag}_{n}^{+}$is observed and so:

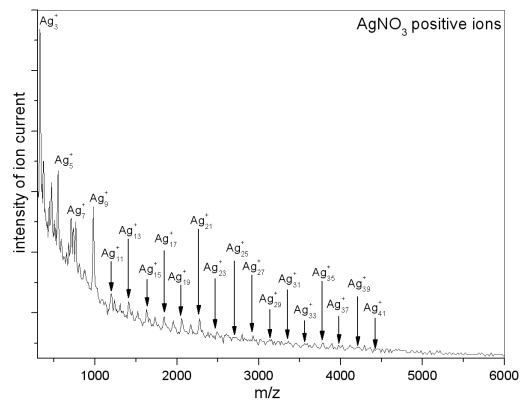

Fig. 6. Positive-ions mass spectra of silver nitrate obtained in matrix assisted laser desorption/ionization.

- in the case of silver nitrate, number $n \leq 41$ (without matrix $\leq 5)($ Fig. 6$)$;
- in the case of silver trifluoroacetate, number $n \leq 59$ (without the matrix $\leq 11)$ (Fig. 7);

- in the case of silver benzoate, number $n \leq 72$ (without the matrix $\leq 45)$ (Fig. 8).

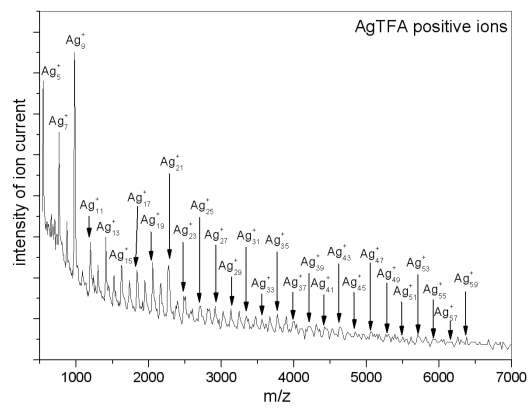

Fig. 7. As in Fig. 6, but for silver trifluoroacetate.

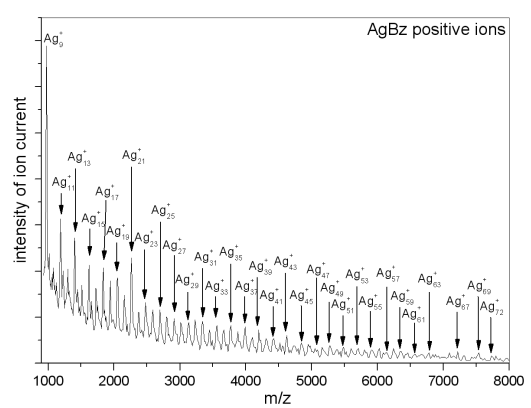

Fig. 8. As in Fig. 6, but for silver benzoate.

As regarding the negative ions, MALDI is a method to improve the number of negative ions produced only in silver benzoate case, although the intensity of the ionic current corresponding to the peaks of the negative ions of silver clusters is small. The number of silver atoms in formed clusters $\mathrm{Ag}_{n}^{-}$with $n<8$ and $12 \leq n \leq 53$. Also it is difficult to distinguish characteristic alternation in the rate of the ionic current due to an even and odd number of silver atoms in the cluster. For a better comparison, these results were brought together and presented in Table II.

For both methods, MALDI and LDI, the rule is that the current intensity of positive ions is greater than the current intensity of negative ions. This might mean that probably in the cold plasma, resulting in the LDI or MALDI process, there is a greater number of $\mathrm{Ag}_{n}^{+}$ions than $\mathrm{Ag}_{n}^{-}$. DHB matrix was chosen deliberately, because productivity of silver atoms clusters increases in the MALDI method, when the matrix has a carboxylic group, such as in the case of DHB [13]. 
TABLE II

Comparison of ions of the largest cluster sizes obtained in LDI and MALDI method, depending on the type of salt used.

\begin{tabular}{c|c|c|c|c|c}
\hline \hline \multirow{2}{*}{ Silver compound } & \multicolumn{2}{|c|}{$\mathrm{Ag}_{n}^{+}$} & \multicolumn{2}{c|}{$\mathrm{Ag}_{n}^{-}$} & \multirow{2}{*}{$\begin{array}{c}\text { Magic clusters } \\
\text { (for positive ions only) }\end{array}$} \\
\cline { 2 - 5 } & MALDI & LDI & MALDI & LDI & 9,21 \\
silver nitrate & 41 & 5 & 4 & 4 & $9,21,35$ \\
silver trifluoroacetate & 59 & 11 & 6 & 5 & $9,21,35$ \\
silver benzoate & 72 & 45 & 53 & 2 &
\end{tabular}

Matrix has a clear impact on the formation of silver clusters for each of the selected silver salt. For example, in the absence of a matrix, positive ions formed as a result of laser desorption/ionization of AgTFA are $\mathrm{Ag}_{n}^{+}$ with $n \leq 11$. If we add the DHB matrix to solution of salt, the positive ions of silver clusters with more atoms are created.

Kéki et al. believe that in the solid phase, there is no reaction between the matrix and silver salt, and it appears in the gas phase. So it is most likely that the formation of silver clusters is in the gas phase [13, 14]. It is presumably that firstly occurs the reduction of $\mathrm{Ag}^{+}$ cations to silver atoms by one of three following reactions $[13,14]$ :

- exchange of charge between the molecules of the matrix (M) and silver cations:

$$
\mathrm{M}+\mathrm{Ag}^{+} \rightarrow \mathrm{M}^{+}+\mathrm{Ag} ;
$$

- exchange of charge between excited matrix molecules $(\mathrm{M})$ and silver cations:

$$
\mathrm{M}^{*}+\mathrm{Ag}^{+} \rightarrow \mathrm{M}^{+}+\mathrm{Ag}
$$

- the least likely to be two-photon absorption by the matrix molecules:

$$
\begin{aligned}
& \mathrm{M}+h \nu \rightarrow \mathrm{M}^{+}+\mathrm{e}^{-}, \\
& \mathrm{Ag}^{+}+\mathrm{e}^{-} \rightarrow \mathrm{Ag} .
\end{aligned}
$$

On the other hand, mass spectra are shown to be quasimolecular ions corresponding to $[\mathrm{M}+\mathrm{Ag}]^{+}$, which is the best testimony to the influence of the matrix and silver salt. Mentioned above, Kéki et al. have found that the process of clustering is much more efficient if more atoms of silver are captured by the matrix molecules [13]. In their work this conclusion is confirmed also by Choi and Ha [15]. They stated that, for AgBz or AgTFA the separation of acid groups and the addition of DHB to the ion/ atom of silver is more likely, which in turn can positively influence the process of clustering. It also could be due to the fact that the 2,5-dihydroxybenzoic acid absorbs laser light with a wavelength of $337 \mathrm{~nm}$ [15]. The matrix can also act similarly to the carrier gas used in the clustering process by using a source based on adiabatic expansion or the aggregation of vapor of gas-metal [13].
In the case of matrix assisted laser desorption/ionization formed in cold plasma, clusters are stabilized by the matrix molecules.

\section{Conclusion}

We investigated the silver clusters ion formation from different silver salts in LDI and MALDI method. On the basis of the experimental results, it can be concluded that silver clusters are created in both LDI and MALDI method depending on silver salt type with difference that in case of MALDI formed species are bigger. Matrix has a clear impact on the formation of silver clusters. On the basis of the experimental results we assume that matrix molecules probably reduce the silver ions and also can act as carrier gas, which has a stabilization effect on formatted species, enhancing the growth of the clusters. In case of laser desorption/ionization, we conclude that probability of silver clusters production is higher when the seeds of diatomic clusters are already in condensed phase (silver benzoate or silver nanopowder).

\section{References}

[1] S.J. Riley, E.K. Parks, C.R. Mao, L.G. Pobo, S. Wexler, J. Phys. Chem. 86, 3911 (1982).

[2] R.E. Smalley, Laser Chem. 2, 167 (1983).

[3] W.A. de Heer, Rev. Mod. Phys. 65, 611 (1993).

[4] C. Staudt, R. Heinrich, A. Wucher, Nucl. Instrum. Methods Phys. Res. B 677, 164 (2000).

[5] W. Begemann, S. Deihöfer, K.H. Meiwes-Broer, H.O. Lutz, Z. Phys. D, At. Mol. Clusters 3, 183 (1986).

[6] Ch.H. Bae, S.H. Nam, S.M. Park, Appl. Surf. Sci. 197, 628 (2002).

[7] R. Brause, H. Möltgen, K. Kleinermanns, Appl. Phys. B 75, 711 (2002).

[8] M. Szymańska-Chargot, A. Gruszecka, A. Smolira, L. Michalak, Vacuum 82, 1088 (2008).

[9] M. Szymańska-Chargot, A. Gruszecka, A. Smolira, K. Bederski, K. Głuch, J. Cytawa, L. Michalak, J. Alloys Comp. 486, 66 (2009).

[10] A. Gruszecka, M. Szymańska-Chargot, A. Smolira, L. Michalak, Vacuum 82, 1083 (2008). 
[11] K. Bederski, M. Szymańska-Chargot, Vacuum 83, 86 (2009).

[12] S.-S. Choi, S.-H. Ha, H.M. Lee, J.-Ch. Kim, Bull. Korean Chem. Soc. 28, 1437 (2007).

[13] S. Keki, L. Szilagyi, J. Torok, G. Deak, M. Zsuga, J. Phys. Chem. B 107, 4818 (2003).

[14] H. Rashidzadeh, B. Guo, Chem. Phys. Lett. 310, 466 (1999).

[15] S.-S. Choi, S.-H. Ha, Bull. Korean. Chem. Soc. 28, 2508 (2007).
[16] A. Bajuk, K. Gluch, L. Michalak, Electronics 8/9, 68 (2001).

[17] K. Gluch, A. Bajuk, L. Michalak, Maintenance Reliability 2/3, 42 (2001).

[18] A. Bajuk, K. Gluch, L. Michalak, Rapid Comm. Mass Spectrom. 15, 2383 (2001).

[19] S. Ptasińska, L. Michalak, M. Smolira, Rapid Comm. Mass Spectrom. 17, 917 (2003). 